\title{
Improvement of human cell line activation test (h-CLAT) using short-time exposure methods for prevention of false-negative results
}

\author{
Kazuto Narita1,2, Yuuki Ishii', Phuc Thi Hong Vo1, Fumiko Nakagawa1, Shinichi Ogata ${ }^{3}$, \\ Kunihiko Yamashita ${ }^{4}$, Hajime Kojima ${ }^{2}$ and Hiroshi Itagaki ${ }^{1}$ \\ 'Department of Chemical and Energy Engineering, Yokohama National University, \\ 79-5 Tokiwadai, Hodogaya-ku, Yokohama 240-8501, Japan \\ ${ }^{2}$ Division of Risk Assessment, National Institute of Health Sciences, \\ 1-18-1 Kamiyoga, Setagaya-ku, Tokyo 158-8501, Japan \\ ${ }^{3}$ Department of Environment and Information Sciences, Yokohama National University, \\ 79-7 Tokiwadai, Hodogaya-ku, Yokohama 240-8501, Japan \\ ${ }^{4}$ Corporate Research Center, Daicel Corporation, 1239 Shinzaike, Aboshi-ku, Hyogo, 671-1283, Japan
}

(Received December 6, 2017; Accepted January 31, 2018)

\begin{abstract}
Recently, animal testing has been affected by increasing ethical, social, and political concerns regarding animal welfare. Several in vitro safety tests for evaluating skin sensitization, such as the human cell line activation test (h-CLAT), have been proposed. However, similar to other tests, the h-CLAT has produced false-negative results, including in tests for acid anhydride and water-insoluble chemicals. In a previous study, we demonstrated that the cause of false-negative results from phthalic anhydride was hydrolysis by an aqueous vehicle, with IL-8 release from THP-1 cells, and that short-time exposure to liquid paraffin (LP) dispersion medium could reduce false-negative results from acid anhydrides. In the present study, we modified the h-CLAT by applying this exposure method. We found that the modified h-CLAT is a promising method for reducing false-negative results obtained from acid anhydrides and chemicals with octanol-water partition coefficients $\left(\log K_{\text {ow }}\right)$ greater than 3.5. Based on the outcomes from the present study, a combination of the original and the modified h-CLAT is suggested for reducing false-negative results. Notably, the combination method provided a sensitivity of $95 \%$ (overall chemicals) or $93 \%$ (chemicals with $\log K_{\text {ow }}>2.0$ ), and an accuracy of $88 \%$ (overall chemicals) or $81 \%$ (chemicals with $\log K_{\text {ow }}>2.0$ ). We found that the combined method is a promising evaluation scheme for reducing false-negative results seen in existing in vitro skin-sensitization tests. In the future, we expect a combination of original and modified h-CLAT to be applied in a newly developed in vitro test for evaluating skin sensitization.
\end{abstract}

Key words: Skin sensitization test, False-negative results, h-CLAT, THP-1, Allergic contact dermatitis

\section{INTRODUCTION}

Skin sensitization, such as allergic contact dermatitis (ACD), is a phenomenon in which rashes occur on the skin owing to complex T-cell-mediated immune responses. ACD is induced by repeated contact with external low-molecular-weight chemicals (e.g., poison ivy/oak and metal allergens).

Recently, animal testing has been affected by increasing ethical, social, and political concerns regarding ani- mal welfare. Several countries have banned safety testing of cosmetic products and their ingredients on animals (Adler et al., 2011). Accordingly, it is necessary to develop alternatives to animal experiments, particularly for in vitro safety testing and skin sensitization evaluation. Several in vitro safety tests have been proposed.

The human cell line activation test (h-CLAT) has been evaluated in a European Union Reference Laboratory for Alternatives to Animal Testing (EURL ECVAM)-coordinated validation study and subsequent independent peer

Correspondence: Hiroshi Itagaki (E-mail: itagaki-hiroshi-dw@ynu.ac.jp) 
review by the EURL ECVAM Scientific Advisory Committee (OECD TG 442E, 2016). The h-CLAT is a mechanistically based in vitro assay that addresses the third key event of the skin sensitization adverse outcome pathway, namely, the activation of skin dendritic cells (DCs). Almost all skin sensitizers have electrophilic properties and covalently bind to nucleophilic sites in skin proteins (Goodwin and Roberts, 1986). Immature DCs recognize sensitizer-protein complexes and become activated. More specifically, sensitizers cause morphological and functional changes in DCs, altering the expression of CD40, CD80, CD83, CD86, and HLA-DR (Aiba et al., 1997; Aiba, 1998; Arrighi et al., 2001; De Smedt et al., 2001). Activated DCs migrate to local lymph nodes and present antigens to naive $\mathrm{T}$ cells, resulting in the proliferation of antigen-specific memory T cells (Weltzien et al., 1996; Banchereau and Steinman, 1998; Enk et al., 1993; Cumberbatch et al., 1997, 2005).

The h-CLAT uses THP-1 cells, a human monocytic leukemia cell line (Tsuchiya et al., 1980), as a replacement for DCs to evaluate changes in CD86 and CD54 expression. CD86 and CD54 are typical markers of monocytic THP-1 activation and may mimic DC activation by skin sensitizers, which plays a critical role in T-cell priming (Rothlein et al., 1986; Symington et al., 1993). Many studies have demonstrated the good predictive performance of the h-CLAT compared with Local Lymph Node Assay (LLNA) results or human data (Ashikaga et al., 2010; Nukada et al., 2011; Takenouchi et al., 2013). However, similar to other in vitro skin sensitization tests, the h-CLAT still shows false-negative results with some chemicals. Thus, for a testing method to fully substitute for animal tests, the problem of false-negative results should be solved.

In the h-CLAT, hydrolyzable chemicals such as phthalic anhydride (PAH) and water-insoluble chemicals tend to produce false-negative results (Ashikaga et al., 2010; Takenouchi et al., 2013). Negative results for test chemicals with octanol-water partition coefficients $\left(\log K_{\text {ow }}\right)$ greater than 3.5 should not be considered valid (OECD TG 442E, 2016). Therefore, evaluation of water-insoluble chemicals is a crucial issue that must be solved in the development of in vitro skin sensitization tests. Limited studies have focused on technical aspects important for reducing false-negative results in the h-CLAT. It is important to elucidate these causes and to improve testing to minimize such results.

In our previous study, we demonstrated that the cause of false-negative results from $\mathrm{PAH}$ was hydrolysis by an aqueous vehicle by measuring IL- 8 release in THP- 1 cells (Narita et al., 2017). We also demonstrated that short- term exposure to liquid paraffin (LP) dispersion medium may be a promising method for evaluating the skin sensitization hazard of acid anhydrides. Although IL-8 protein release by THP-1 cells has been suggested as a promising biomarker of skin sensitization, it is not measured in internationally accepted in vitro skin sensitization tests. Therefore, the method of short-term exposure to LP medium was applied to the h-CLAT, and the effectiveness of this method was evaluated.

In this study, based on the results of our previous study (Narita et al., 2017), we test the hypothesis that LP medium can improve false-negative results of acid anhydrides and water-insoluble chemicals in the h-CLAT. Furthermore, we demonstrated that a combination of the original h-CLAT and our modified h-CLAT reduced false-negative results.

\section{MATERIALS AND METHODS}

\section{Cells}

THP-1 cells (American Type Culture Collection, Manassas, VA, USA) were cultured in RPMI1640 (Thermo Fisher Scientific, Inc., Waltham, MA, USA) supplemented with $10 \%(\mathrm{v} / \mathrm{v})$ heat-inactivated fetal bovine serum (Thermo Fisher Scientific), 100 units/mL penicillin (Wako Pure Chemical Industries, Ltd., Tokyo, Japan), $100 \mu \mathrm{g} / \mathrm{mL}$ streptomycin (Wako Pure Chemical Industries, Ltd.), and $0.05 \mathrm{mM}$ 2-mercaptoethanol (Thermo Fisher Scientific) at $37^{\circ} \mathrm{C}$ with $5 \% \mathrm{CO}_{2}$. THP-1 cells were routinely passaged and maintained at densities of 1-8 $\times 10^{5}$ cells $/ \mathrm{mL}$. Cells were used before passage 30 for all experiments.

\section{Chemicals}

The test chemicals are listed in Table 1 along with their Chemical Abstracts Service (CAS) numbers, $\log K_{\text {ow }}$ values calculated with KOWWIN ver. 1.68 in EPI Suite (Environmental Protection Agency, Washington, DC, USA), skin sensitization potencies based on EC3 LLNA values, and results from clinical case reports, patch tests, and human maximization tests. Nickel sulfate $\left(\mathrm{NiSO}_{4}\right.$; $>98 \%$ ), PAH (>99\%), maleic anhydride (MAH; > 99\%), benzoic acid (>99.5\%), and cyclamen aldehyde (CA; > $95 \%$ ) were purchased from Sigma-Aldrich Co. (St. Louis, MO, USA). Citral (CI; > 95.0\%), phthalic acid (PA; $>99.0 \%$ ), dimethyl sulfoxide, and LP were purchased from Wako Pure Chemical Industries, Ltd. Phenyl glycidyl ether (PGE; > 99.0\%), butyl glycidyl ether (BGE; $>98.0 \%$ ), benzyl benzoate (BB; > 99.0\%), benzyl cinnamate $(\mathrm{BC} ;>98.0 \%), 10$-undecenal $(10-\mathrm{Un} ;>95.0 \%)$, $N, N$-dibutylaniline (DBA; $>98.0 \%$ ), hexyl cinnamic aldehyde (HCA; > 90.0\%), and dibutyl phthalate (DBP; 
Modified h-CLAT reduces false negatives in skin sensitization tests

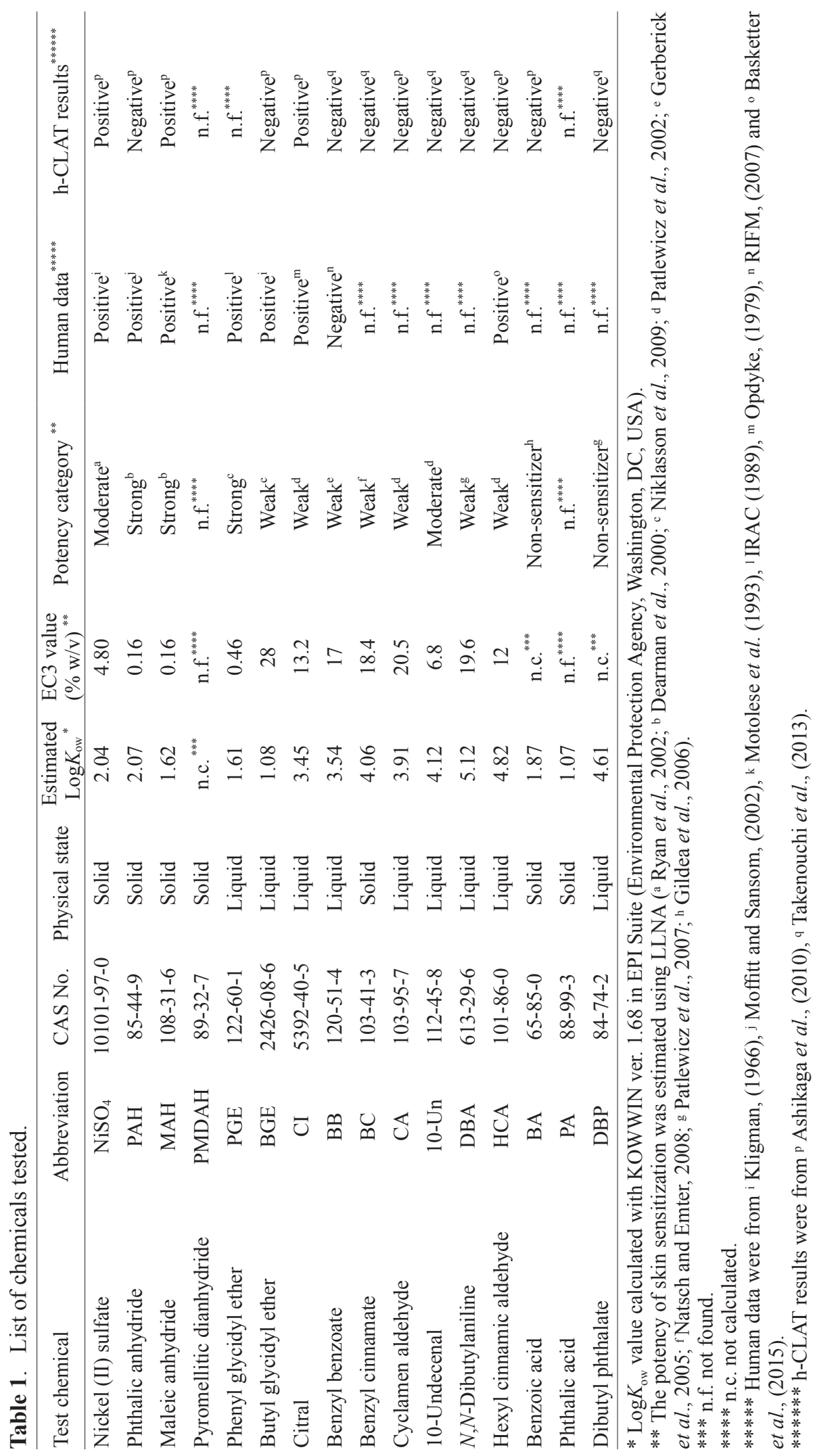

Vol. 43 No. 3 
$>97.0 \%$ ) were purchased from Tokyo Chemical Industry Co., Ltd. (Tokyo, Japan).

\section{Preparation of chemicals and chemical exposure of THP-1 cells}

The LP medium 5-min exposure method was performed as we reported previously (Narita et al., 2017). Briefly, test chemicals were first dispersed in LP and diluted. THP-1 cells were then directly exposed to these suspensions $\left(1 \times 10^{6}\right.$ cells in $100 \mu \mathrm{L}$ suspension $)$ and mixed using a vortex mixer for $5 \mathrm{~min}$ at room temperature. After exposure, the cells were washed and resuspended in $1 \mathrm{~mL}$ of culture medium. Cell suspensions were transferred to individual wells of a 24 -well plate, and the plates were then incubated for $24 \mathrm{hr}$ at $37^{\circ} \mathrm{C}$ in an atmosphere containing $5 \% \mathrm{CO}_{2}$.

\section{Cytotoxicity assay and detection of CD86 and CD54 expression}

The following procedure was conducted according to the h-CLAT protocol (OECD TG 442E, 2016). After chemical exposure and incubation, cells were washed twice with phosphate-buffered saline containing $0.1 \%$ (w/v) bovine serum albumin. Cells were then treated with $0.01 \%$ globulins and Cohn fraction II, III (SigmaAldrich) to block Fc receptors. After blocking, the cells were stained with $0.625 \mu \mathrm{g} / \mathrm{mL}$ propidium iodide (PI, Sigma-Aldrich) and antibodies. The cells were analyzed by flow cytometry (FACSCalibur; Becton Dickinson, Franklin Lakes, NJ, USA), and CELLQUEST was used for analysis. In cell viability measurements, PI-negative cells were defined as living cells. Dead cells were gated out by PI staining. Cell were stained using a fluorescein isothiocyanate (FITC)-labeled mouse monoclonal antihuman CD86 antibody (clone Fun-1; PharMingen, San Diego, CA, USA) and a FITC-labeled mouse monoclonal anti-human CD54 antibody (clone 6.5B5; PharMingen). A FITC-labeled mouse $\mathrm{IgG}_{1}$ was purchased from DAKO (clone: DAK-G01, Glostrup, Denmark) and used as an isotype control. Ten thousand live cells were analyzed for each sample. The relative fluorescence intensity (RFI) was used as an indicator of CD86 and CD54 expression and was calculated from the mean fluorescence intensity (MFI) as follows:

RFI $(\%)=\frac{(\text { MFI of chemical }- \text { exposed cells })-(\text { MFI of chemical }- \text { exposed isotype control cells })}{(\text { MFI of vehicle }- \text { exposed cells })-(\text { MFI of vehicle-exposed isotype control cells })} \times 100$

\section{Statistics}

The assays were performed at least three times. The data are expressed as the mean \pm standard deviation (S.D.). One-way analysis of variance followed by
Dunnett's post-hoc test was used to evaluate statistical significance using EZR (Kanda, 2013), a graphical user interface for R (The R Foundation for Statistical Computing, version 3.3.0). For comparisons with data from vehicle-treated cells, differences with $\mathrm{p}$ values less than $0.05(*)$ and $0.01(* *)$ were considered statistically significant. The predictive performance of the test was calculated according to Cooper statistics as the sensitivity, specificity, and accuracy (Cooper et al., 1979). Sensitivity is the percentage of sensitizers predicted as positive, specificity is the percentage of non-sensitizers predicted as negative, and accuracy is the overall percentage of correct predictions.

\section{RESULTS}

\section{Effect of LP on CD86 and CD54 expression in THP-1 cells}

The effects of LP on cell viability, CD86 expression, CD54 expression, and non-specific antibody adsorption to THP-1 cells were studied. THP-1 cells were treated with LP for $5 \mathrm{~min}$. After exposure to LP, the cells were washed and cultured for $24 \mathrm{hr}$ in culture medium. The results showed no significant differences between the levels of these biomarkers in LP-exposed and unexposed cells in any of the seven replicate experiments (Fig. 1).

Next, the effects of LP dispersion medium on CD86 and CD54 expression in THP-1 cells were examined. THP-1 cells were treated with $\mathrm{NiSO}_{4}$, which was judged positive by the h-CLAT, and benzoic acid, which was judged negative by the h-CLAT in LP dispersion medium. RFI values for CD86 and CD54 expression were then calculated, and the results showed that exposure to $75 \mu \mathrm{g} / \mathrm{mL}$ of $\mathrm{NiSO}_{4}$ significantly augmented the RFI values of CD86 (161 $\pm 32 \%)$ and CD54 (1049 $\pm 283 \%)$ expression (Fig. 2A). Cell viability decreased dose-dependently with benzoic acid treatment at three concentrations $(1.4,1.7$, and $2.0 \mathrm{mg} / \mathrm{mL})$; however, the RFIs of CD86 and CD54 still did not meet the positive criteria for the h-CLAT (150\% and 200\%, respectively; Fig. 2B).

\section{Improvement in false-negative $\mathrm{h}$-CLAT results by a 5-min exposure to hydrolyzable chemicals in LP dispersion medium}

Previously, we observed that PAH significantly increased IL-8 release in LP dispersion medium (Narita et al., 2017). Because PAH also showed false-negative h-CLAT results, we examined whether hydrolyzable chemicals such as PAH augment CD86 and CD54 expression, using LP dispersion medium. The results showed that exposure to $625 \mu \mathrm{g} / \mathrm{mL}$ of $\mathrm{MAH}$, which showed 
Modified h-CLAT reduces false negatives in skin sensitization tests

a true-positive h-CLAT result, significantly augmented the RFI values of both CD86 (205 $\pm 39 \%)$ and CD54 (427 $\pm 39 \%$; Fig. 3A). Notably, $156 \mu \mathrm{g} / \mathrm{mL}$ and $313 \mu \mathrm{g} / \mathrm{mL}$ of $\mathrm{PAH}$, which showed a false-negative

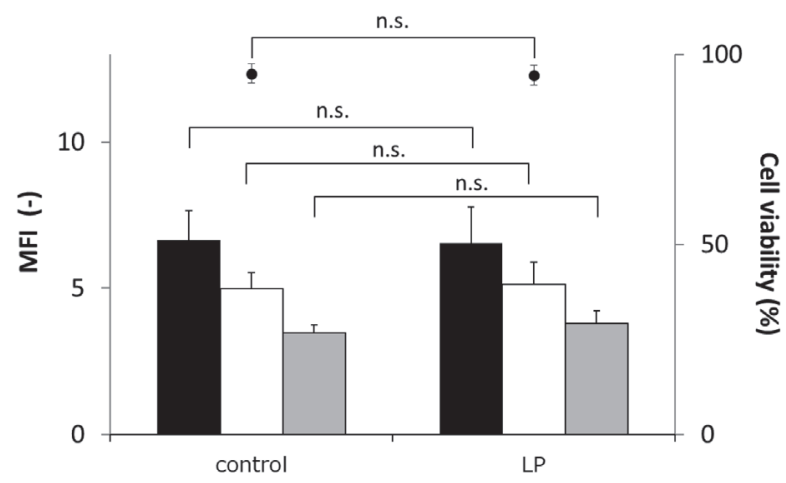

Fig. 1. Effect of LP on CD86 expression, CD54 expression, and non-specific antibody adsorption. THP-1 cells were cultured in medium for $24 \mathrm{hr}$ (control) or for an additional $24 \mathrm{hr}$ after a 5 -min exposure to LP (LP). After incubation, the expression of cell-surface antigens (CD86 [black bars], CD54 [white bars], and non-specific antibody adsorption [gray bars]) was analyzed by flow cytometry, and dead cells were gated out by PI staining as a measure of cell viability (black dots). The results are expressed as the MFI and are presented as means \pm S.D. $(\mathrm{N}=7)$. The results are representative of seven independent experiments. Statistical significance was calculated by Student's t-test (n.s.: not significant).

A

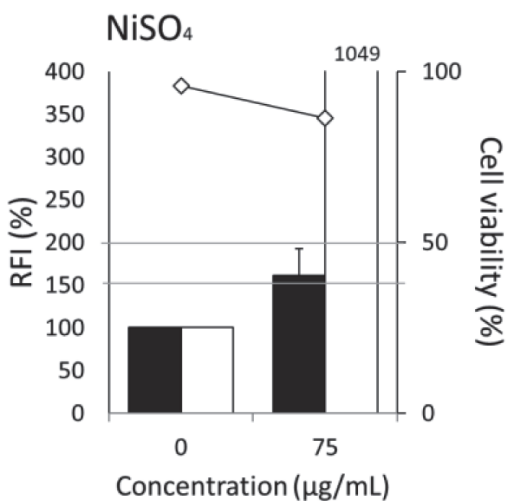

h-CLAT result, augmented the RFI value of CD54 $(281 \pm 82 \%$ and $303 \pm 133 \%)$ (Fig. 3B). Similarly, PMDAH, which showed a false-negative h-CLAT result (data not shown), significantly augmented the RFI values of both CD86 (maximum value: $170 \pm 68 \%$; exposure concentration: $625 \mu \mathrm{g} / \mathrm{mL}$ ) and CD54 (maximum value: $1,033 \pm 371 \%$; exposure concentration: $625 \mu \mathrm{g} / \mathrm{mL}$; Fig. 3C).

However, although cell viability decreased dose-dependently with PA (Fig. 3D), PGE (Fig. 3E), and BGE (Fig. 3F) treatment, the RFIs of CD86 and CD54 still did not meet the positive criteria for the h-CLAT (150\% and $200 \%$, respectively).

\section{Reduction of false-negative $\mathrm{h}$-CLAT results after a 5-min exposure to water-insoluble chemicals in LP medium}

To evaluate water-insoluble chemicals in the h-CLAT, we optimized the 5-min exposure of LP medium method. We investigated the optimal exposure concentration using CI (Fig. 4A). Even though CI is a water-insoluble chemical $\left(\log K_{\text {ow }}=3.45\right)$, CI was classified as a skin sensitizer by the LLNA and h-CLAT. The results showed that when cell viability was more than $50 \%$, the maximum RFI value of CD86 was $203 \pm 52 \%$ (exposure concentration: $15 \mathrm{mg} / \mathrm{mL}$; cell viability: $73 \pm 7.4 \%$ ), and the maximum RFI value of CD54 was $282 \pm 49 \%$ (exposure concentration: $13 \mathrm{mg} / \mathrm{mL}$; cell viability: $81 \pm 0.2 \%)$. Similar to the treatment with $13 \mathrm{mg} / \mathrm{mL}$ of CI, $15 \mathrm{mg} / \mathrm{mL}$ of CI aug-

Fig. 2. Evaluation of water-soluble chemicals. THP-1 cells were cultured in medium for an additional 24 hr after a 5-min exposure to $75 \mu \mathrm{g} / \mathrm{mL}$ of $\mathrm{NiSO}_{4}$ (A) and various concentrations of BA (B) in LP dispersion medium. After incubation, the expression of cell-surface antigens (CD86 [black bars] and CD54 [white bars]) was analyzed by flow cytometry, and dead cells were gated out by staining with PI (white diamonds). The assay was conducted according to the h-CLAT protocol. The results are expressed as RFI and presented as means \pm S.D. $(\mathrm{N}=3)$. The results are representative of three independent experiments. The lines across the graph indicate RFI values of 150 and 200. 
A

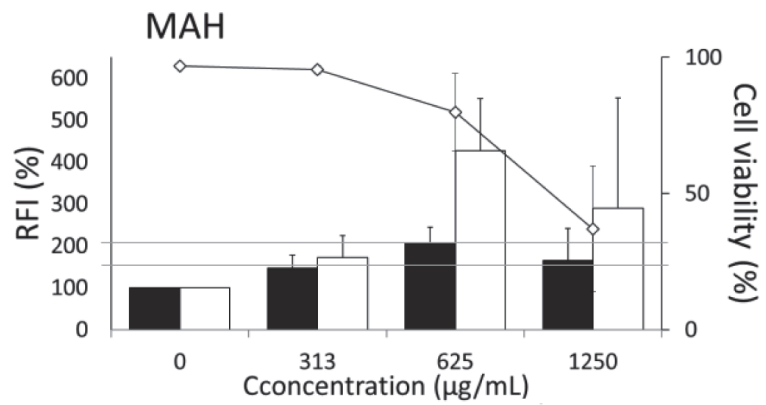

C

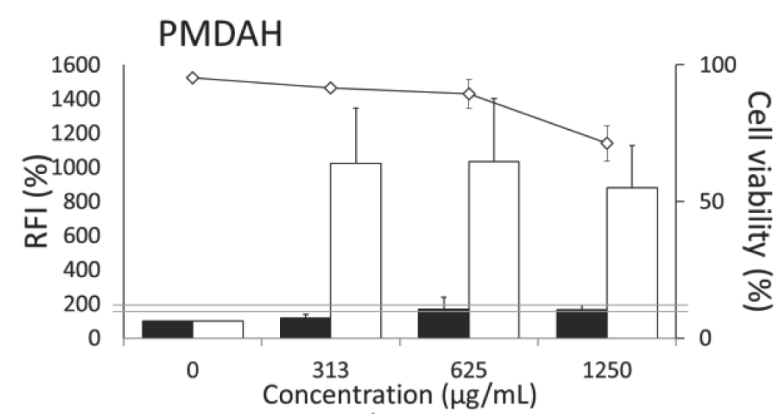

E

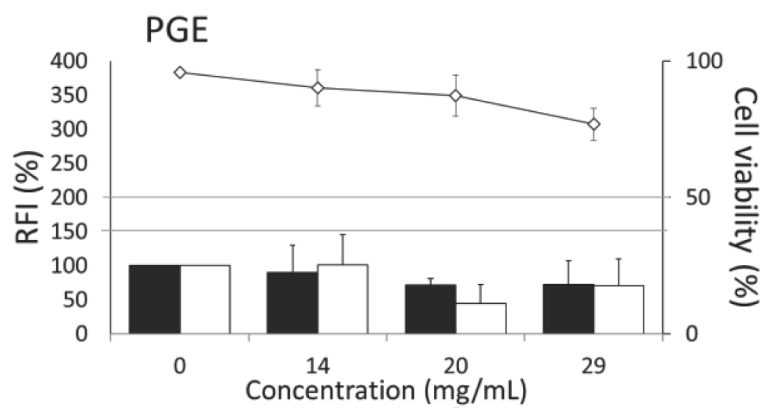

B

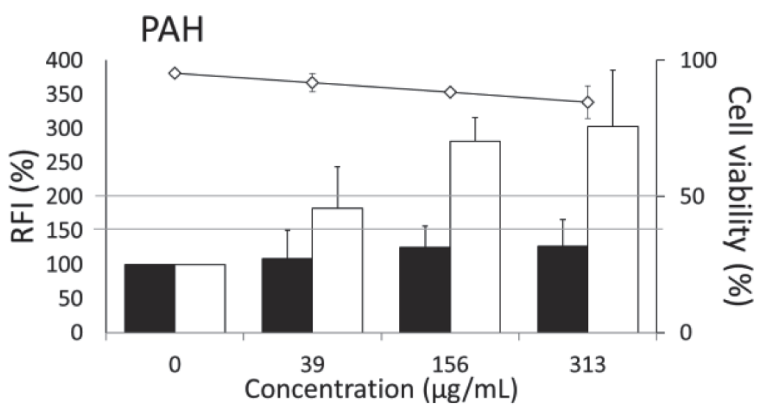

D

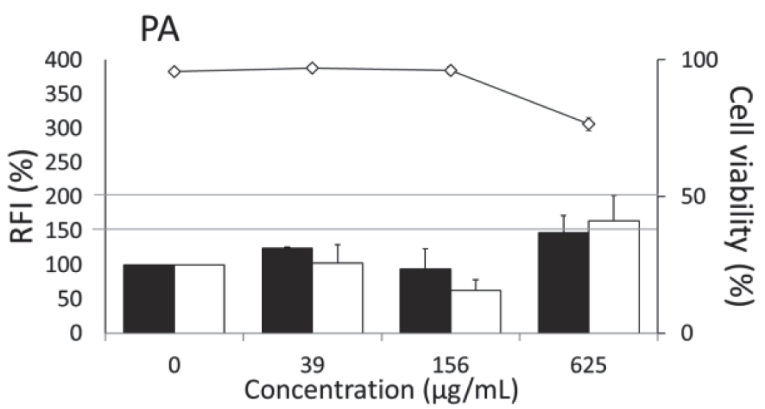

F

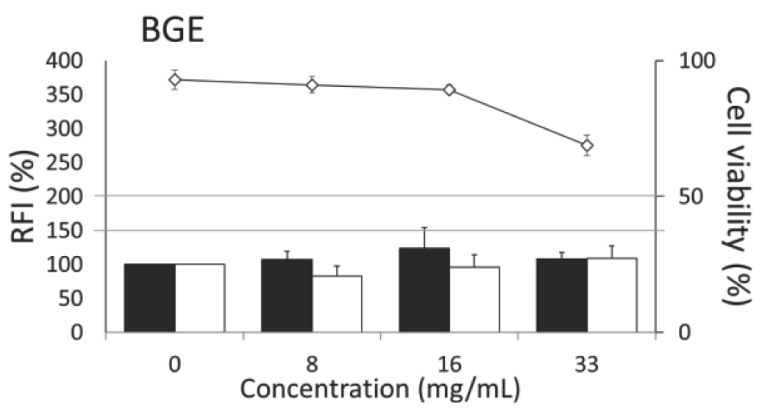

Fig. 3. Evaluation of acid anhydrides and epoxides. THP-1 cells were cultured in medium for an additional $24 \mathrm{hr}$ after a 5 -min exposure to various concentrations of MAH (A), PAH (B), PMDAH (C), PA (D), PGE (E), and BGE (F) in LP dispersion medium. After incubation, the expression of cell-surface antigens (CD86 [black bars] and CD54 [white bars]) was analyzed by flow cytometry, and dead cells were gated out by staining with PI (white diamonds). The assay was conducted according to the h-CLAT protocol. The results expressed as the RFI and are presented as means \pm S.D. $(N=3)$. The results are representative of three independent experiments. The lines across the graph indicate RFI values of 150 and 200.

mented the RFI value of CD54 (277 $\pm 66 \%)$. Next, we investigated the optimal post-culture time of THP-1 cells after a 5 -min exposure in LP medium using $15 \mathrm{mg} / \mathrm{mL}$ CI (Fig. 4B). The results showed that there was no obvious change in cytotoxicity, CD86 expression, or CD54 expression immediately after exposure. CI induced cytotoxicity and augmentation of CD86 expression in THP-1 cell cultures in a time-dependent manner for up to $24 \mathrm{hr}$. Notably, CI augmented CD54 expression in a time-dependent manner for up to $48 \mathrm{hr}$. At $48 \mathrm{hr}$, the maximum RFI value of CD54 (587 $\pm 142 \%)$ was observed.

To evaluate water-insoluble chemicals, we used the exposure concentration corresponding to $75 \%$ cell viability, and $24 \mathrm{hr}$ and $48 \mathrm{hr}$ post-culture times for CD86 and 
Modified h-CLAT reduces false negatives in skin sensitization tests

A

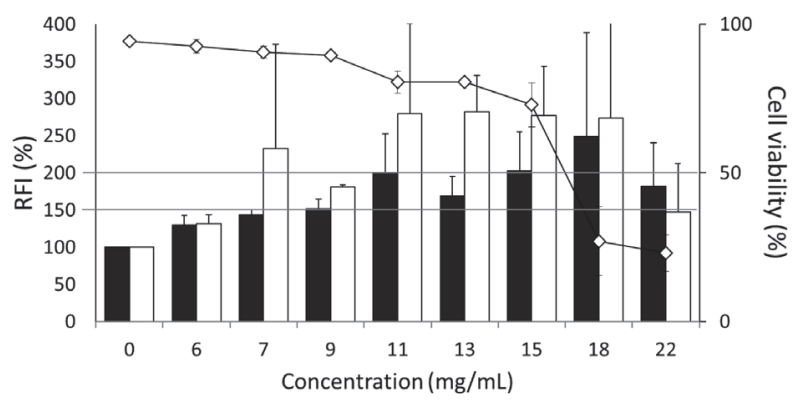

B

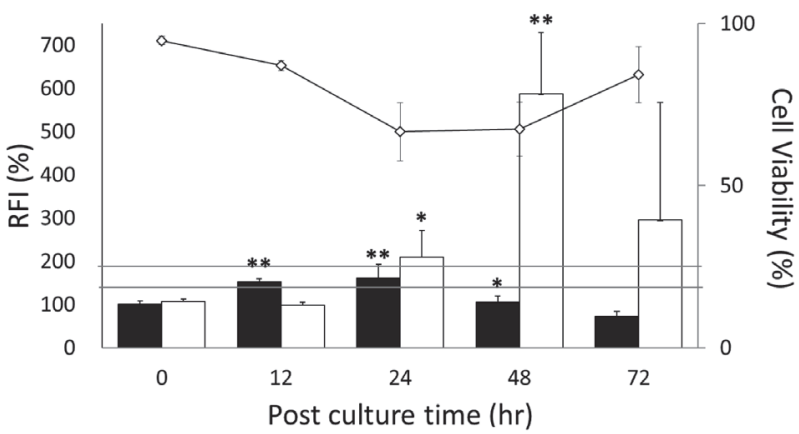

Fig. 4. Determination of the optimal exposure concentration (A) and post-culture time (B) for increasing CD86 and CD54 expression when evaluating water-insoluble chemicals. THP-1 cells were cultured in medium for an additional $24 \mathrm{hr}$ after a 5 -min exposure to various concentrations of CI (A) or for various post-culture times after a 5 -min exposure to $15 \mathrm{mg} / \mathrm{mL} \mathrm{CI} \mathrm{(B)} \mathrm{in}$ LP medium. After incubation, the expression of cellsurface antigens (CD86 [black bars] and CD54 [white bars]) was analyzed by flow cytometry, and dead cells were gated out by staining with PI (white diamonds). The assay was conducted according to the h-CLAT protocol. The results are expressed as the RFI and are presented as means \pm S.D. $(\mathrm{N}=3)$. Statistical significance was calculated by one-way ANOVA followed by Dunnett's post-hoc test, compared with the control group $(* p<0.05, * * p<0.01)$. The results are representative of three independent experiments. The lines across the graph indicate RFI values of 150 and 200.

CD54, respectively. Under these conditions, we examined whether water-insoluble chemicals, which produced false negative results in the h-CLAT, augmented CD86 and CD54 expression using LP medium (Fig. 5). The results showed that $10-\mathrm{Un}(76 \mathrm{mg} / \mathrm{mL})$ and CA $(62.5 \mathrm{mg} / \mathrm{mL})$ augmented the RFI value of CD54 (209 $\pm 78 \%$ and $256 \pm 25 \%$, respectively). Similarly, BB $(62.5 \mathrm{mg} / \mathrm{mL})$ and $\mathrm{BC}(125 \mathrm{mg} / \mathrm{mL})$ augmented the RFI value of CD86 (151 $\pm 27 \%$ and $235 \pm 59 \%$, respectively). When we stimulated THP-1 cells with $250 \mathrm{mg} / \mathrm{mL}$ of DBP as a negative control, the RFIs of CD86 and CD54 did not meet the positive criteria for the h-CLAT $(150 \%$ and $200 \%$, respectively). On the other hand, after treatment with DBA (Fig. 5B) and HCA (Fig. 5C), which were judged as false negatives by the h-CLAT, the RFIs of CD86 and CD54 did not meet the positive criteria for the h-CLAT $(150 \%$ and $200 \%$, respectively).

\section{Performance of the combination of h-CLAT and modified $\mathrm{h}$-CLAT}

Based on the above findings, we demonstrated that combining the original and modified h-CLATs reduced false-negative results (Fig. 6), as follows.

1. The modified h-CLAT was performed with chemicals judged negative by the h-CLAT, considering the possibility of false-negative results.

2. A hydrolyzability check for each test chemical was performed. If the test chemical was hydrolyzable under the conditions of the h-CLAT, then the modified h-CLAT was performed regardless of the solubility in LP.

3. If the modified h-CLAT gave a positive result, then hydrolysis was considered the cause of the false negative, and the test chemical was considered a sensitizer.

4. If the test chemical was not hydrolyzable under the h-CLAT conditions or if its hydrolyzability was unknown, then the $\log K_{\text {ow }}$ value of the test chemical was investigated.

5. If the $\log K_{\text {ow }}$ value was over 2.0, then a solubility check in LP was performed.

6. If the chemical was soluble at $500 \mathrm{mg} / \mathrm{mL}$ in LP, then a modified h-CLAT was performed.

7. If the modified h-CLAT gave a positive result, then water-insolubility was considered the cause of the false negative, and the test chemical was considered a sensitizer.

8. If the modified h-CLAT gave a negative result, then the test chemical was not considered a sensitizer.

9. If the chemical was not soluble at $500 \mathrm{mg} / \mathrm{mL}$ in LP, then it was unevaluable by this testing approach.

Following this tiered system, chemicals judged as negative by the h-CLAT were reevaluated by the modified h-CLAT following a hydrolyzable or lipophilicity check. Comparisons of the predictive performance of the h-CLAT alone and of this tiered system with that of LLNA using a previous data set (Ashikaga et al., 2010; Nukada et al., 2011; Takenouchi et al., 2013) are sum- 


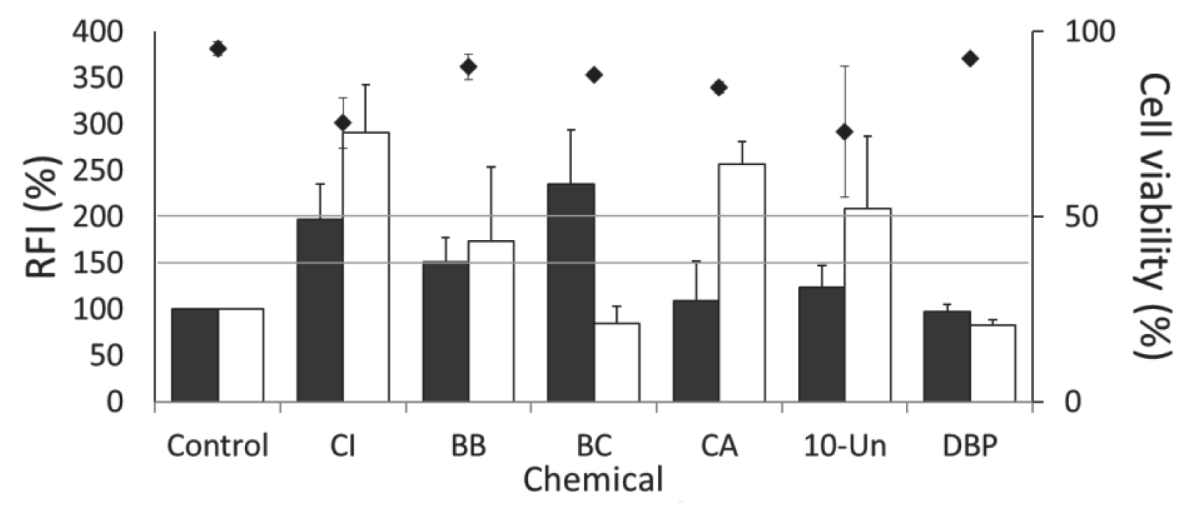

B

$\mathrm{C}$
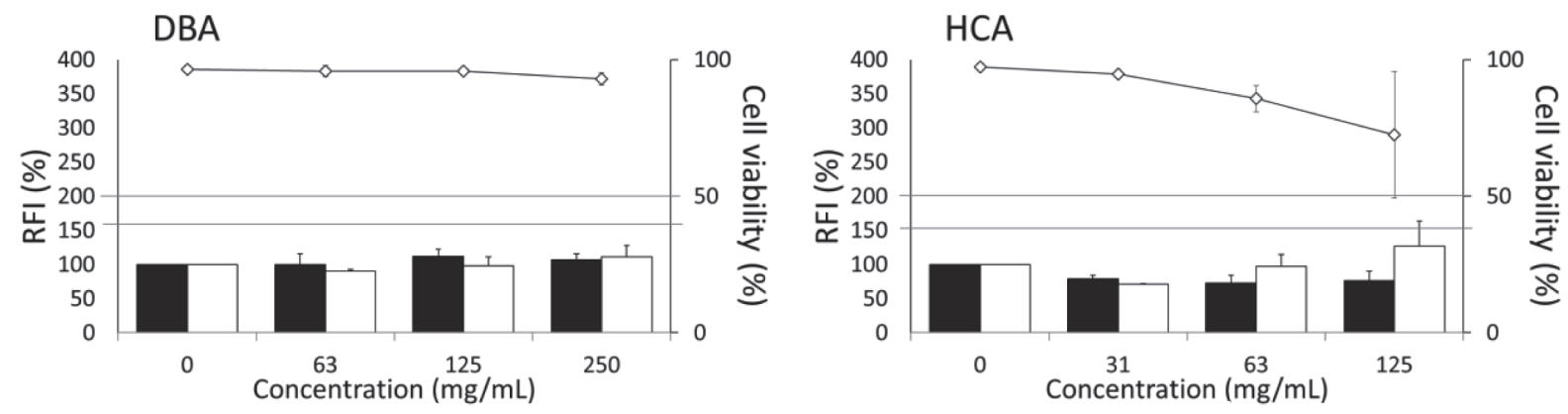

Fig. 5. Evaluation of water-insoluble chemicals. THP-1 cells were cultured in medium for an additional $24 \mathrm{hr}$ after a 5-min exposure to $15 \mathrm{mg} / \mathrm{mL}$ of CI, $62.5 \mathrm{mg} / \mathrm{mL}$ of BB, $125 \mathrm{mg} / \mathrm{mL}$ of BC, $62.5 \mathrm{mg} / \mathrm{mL}$ of CA, $76 \mathrm{mg} / \mathrm{mL}$ of $10-\mathrm{Un}$, or $250 \mathrm{mg} / \mathrm{mL}$ of DBP (A), or various concentrations of DBA (B) or HCA (C) in LP medium. After incubation, the expression of cell-surface antigens (CD86 [black bars] and CD54 [white bars]) was analyzed by flow cytometry, and dead cells were gated out by staining with PI (white diamonds). The assay was conducted according to the h-CLAT protocol. The results are expressed as the RFI and are presented as means \pm S.D. $(\mathrm{N}=3)$. The results are representative of three independent experiments. The lines across the graph indicate RFI values of 150 and 200.

marized in Tables 2 and 3. However, methylchloroisothiazolinone/methylisothiazolinone, $\mathrm{NiSO}_{4}$, and dextran (whose $\log K_{\text {ow }}$ values could not be calculated by KOWWIN) and tocopherol (for which false positive results in LLNA have been reported [Basketter et al., 2014]), were excluded. Notably, this tiered system provided a sensitivity of $95 \%$ (overall chemicals) or $93 \%$ (chemicals with a $\log K_{\text {ow }}>2.0$ ) and an accuracy of $88 \%$ (overall chemicals) or $81 \%$ (chemicals with a $\log K_{\text {ow }}>2.0$ ). These data reflect a reduction in false-negative results. Moreover, no new produced false-positive results were observed using the tiered system.

\section{DISCUSSION}

In our previous study, we reported that PAH significantly increased IL-8 release using LP dispersion medium (Narita et al., 2017). In this study, we aimed to prevent false-negative results in the h-CLAT using a short-term exposure method in LP medium.

Like other in vitro skin sensitization tests, the h-CLAT still produces false-negative results. It has been reported that the h-CLAT shows high predictive performance when analyzing chemicals with $\log K_{\text {ow }}$ values less than 2.0 (Ashikaga et al., 2010; Nukada et al., 2011; Takenouchi et al., 2013). These results showed that the 
Modified h-CLAT reduces false negatives in skin sensitization tests

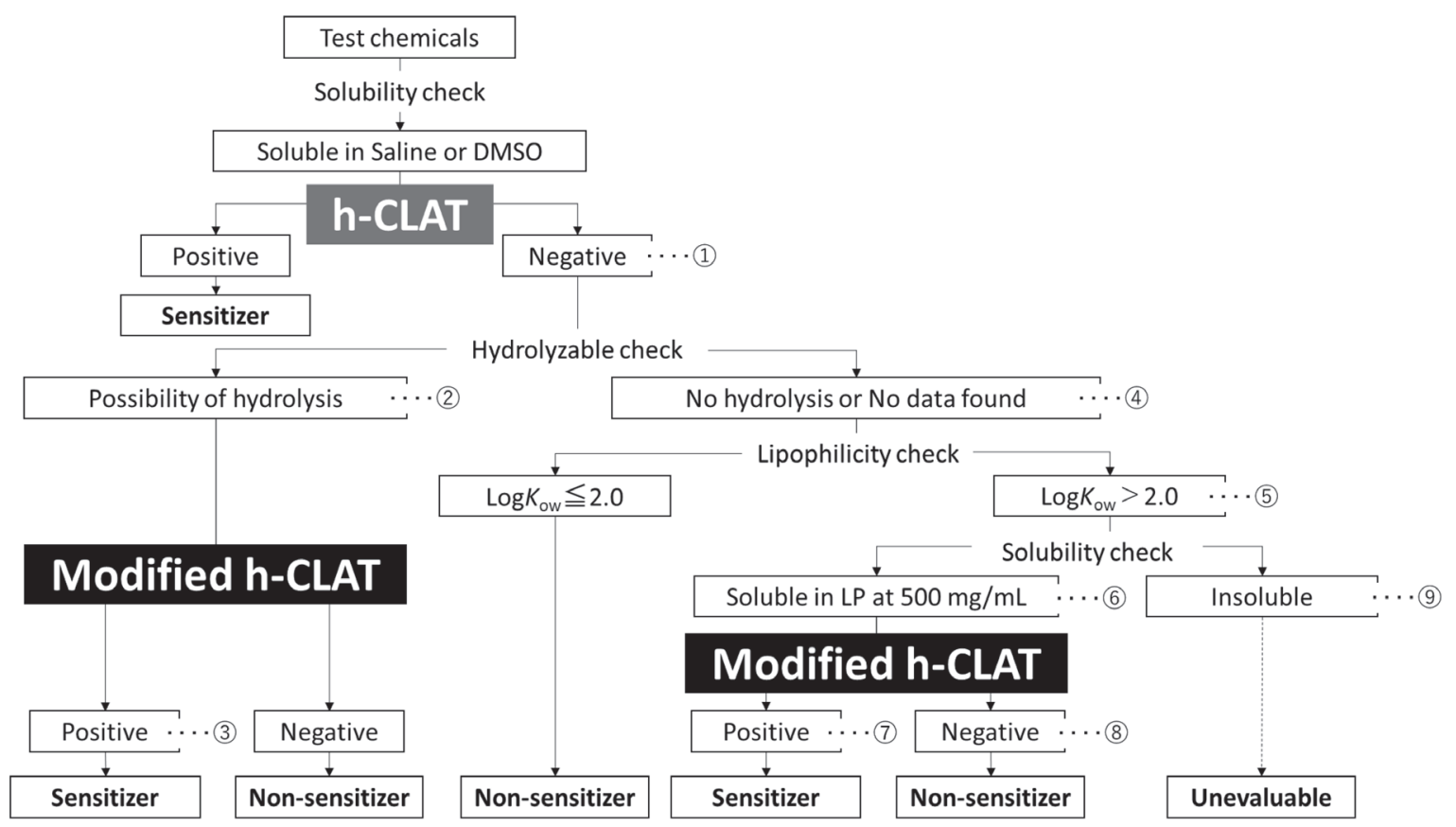

Fig. 6. Combination of h-CLAT and modified h-CLAT. The modified h-CLAT involved a 5-min exposure using LP medium methods applied to the h-CLAT.

Table 2. Predictive performance of the h-CLAT and tiered systems compared with LLNA.

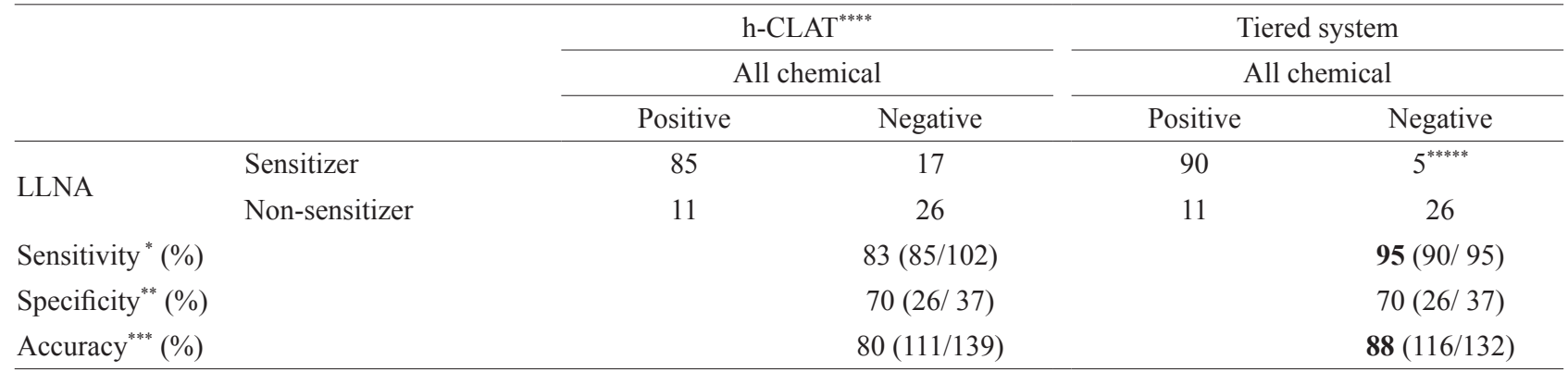

* The percentage of chemicals correctly evaluated as sensitizers by the h-CLAT, compared to that by LLNA.

** The percentage of chemicals correctly evaluated as non-sensitizers by the h-CLAT, compared that by to LLNA.

*** The percentage of chemicals correctly evaluated by the h-CLAT, compared to that by LLNA.

${ }^{* * * *}$ h-CLAT data are based on Ashikaga et al., (2010), Nukada et al., (2012), and Takenouchi et al. (2013) for the chemicals listed, except for methylchloroisothiazolinone/methylisothiazolinone, $\mathrm{NiSO}_{4}$, tocopherol, and dextran.

${ }^{* * * * *}$ Seven chemicals unevaluable by the tiered testing approach were excluded from statistical analysis.

accuracy for 74 chemicals tested with the h-CLAT was $93 \%$, the sensitivity was $96 \%$, and the specificity was $88 \%$. However, the test has tended to produce false-negative results in tests for water-insoluble chemicals, especially chemicals with $\log K_{\mathrm{ow}}$ values greater than 2.0, based on data from its developers. Therefore, we defined water-insoluble chemicals as those with $\log K_{\text {ow }}$ values greater than 2.0.

We hypothesized that short-term exposure in LP medium could overcome the lingering problem of false-negative results for water-insoluble chemicals. Therefore, we applied a short-time exposure in LP medium method to the h-CLAT and established an in vitro skin sensitization test. Using this method, we correctly evaluated the 
Table 3. Predictive performance comparison of the tiered system with LLNA for chemicals according to Log $K_{\text {ow }}$ value.

\begin{tabular}{llcccc}
\hline & & \multicolumn{3}{c}{ Tiered system } \\
\cline { 3 - 5 } & & \multicolumn{2}{c}{ Chemicals with $\log K_{\text {ow }}>2.0$} & \multicolumn{2}{c}{ Chemicals with $\log K_{\text {ow }} \leq 2.0$} \\
\cline { 3 - 5 } & & Positive & Negative & Positive & Negative \\
\hline \multirow{2}{*}{ LLNA } & Sensitizer & 42 & 3 & 48 & 2 \\
Sensitivity (\%) & Non-sensitizer & 8 & 5 & 3 & 21 \\
Specificity (\%) & & & $33(42 / 45)$ & $96(48 / 50)$ \\
Accuracy (\%) & & $38(5 / 13)$ & $88(21 / 24)$ \\
\hline
\end{tabular}

skin sensitization potential of $\mathrm{NiSO}_{4}, \mathrm{CI}$, and BA. These results indicated that the biomarkers and testing criteria of the ordinary h-CLAT were applicable with the modified h-CLAT involving a 5-min exposure in LP medium. Furthermore, the modified h-CLAT may be a promising method for evaluating the skin sensitization potential of acid anhydrides; we conclude that the false-negative results for PAH and PMDAH in the h-CLAT were caused by hydrolysis by an aqueous vehicle.

The h-CLAT produced false-negative results for PGE (data not shown) and BGE (Ashikaga et al., 2010), and these results were not due to hydrolysis by an aqueous vehicle. The half-lives for PGE and BGE hydrolysis at $25^{\circ} \mathrm{C}$ and $\mathrm{pH}=7$ were $2.2 \times 10^{6} \mathrm{hr}$ and $5.4 \times 10^{5} \mathrm{hr}$, respectively (HYDROWIN ver. 2.00 in EPI suite); thus, it is unlikely that PGE or BGE hydrolysis occurred during the h-CLAT procedure. PGE and BGE were still evaluated as false-negatives by the modified h-CLAT. Because the ARE-Nrf2 luciferase test correctly evaluates PGE and BGE as positives (Delaine et al., 2011), the cause of this difference for epoxides may be associated specifically with THP-1 cells or with CD86 and CD54.

Chemicals used in this study with high $\log K_{\text {ow }}$ values were observed to have lower skin sensitization potentials because these chemicals precipitate or separate out from the aqueous vehicle in almost all in vitro skin sensitization tests. Notably, in the modified h-CLAT, we found that $\mathrm{BB}, \mathrm{BC}, \mathrm{CA}$, and 10-Un augmented CD86 or CD54 expression in THP-1 cells. On the other hand, DBA and HCA were still evaluated as false-negatives by the modified h-CLAT. It is likely that DBA is a pro-hapten, because DBA was evaluated as positive by the ARENrf2 luciferase test in the presence of rat liver S9 fractions (Natsch and Haupt, 2013). Therefore, LP medium exposure may be unsuitable for evaluating pro-haptens correctly. HCA was classified as a weaker skin sensitizer than predicted by LLNA (Basketter et al., 2014). It possesses a low capacity to induce skin sensitization under consumer-exposure conditions (Basketter et al., 2015).
$\mathrm{BB}$ has been placed in the same category, as a rare cause of contact allergy except perhaps in special circumstances. This can be attributed to its very slight augmentation of CD86 expression on the BB-treated cells.

However, LP-insoluble chemicals, especially solid, water-insoluble chemicals (except for BC), cannot be evaluated by the modified h-CLAT. Accordingly, additional studies are needed to develop methods for the study of solid, water-insoluble chemicals.

In this study, the combination of the h-CLAT and modified h-CLAT provided high sensitivity and accuracy. We demonstrated the high predictive performance of the combined method, despite including some chemicals with $\log K_{\text {ow }}$ values greater than 3.5. We believe that these results are due to the following three factors: the h-CLAT correctly evaluated chemicals with $\log K_{\text {ow }}$ values less than 2.0 (Ashikaga et al., 2010; Nukada et al., 2011; Takenouchi et al., 2013), the application limits of the h-CLAT (e.g., on water-insoluble or hydrolyzable compounds) were clear (Ashikaga et al., 2010; Takenouchi et al., 2013), and the modified h-CLAT reduced false-negative results obtained for water-insoluble or hydrolyzable chemicals. When we defined water-insoluble chemicals as those with $\log K_{\text {ow }}$ values greater than 3.5, this tiered system provided a sensitivity of $90 \%$ (24 chemicals with $\log K_{\text {ow }}>3.5$ ). However, the sensitivity was slightly lower than those with $\log K_{\text {ow }}$ value $=2.0$, even though the number of the test chemicals was increased.

In conclusion, we found that the combined use of the h-CLAT and modified h-CLAT is a promising evaluation scheme that reduces the false-negative results seen in existing in vitro skin sensitization tests. Our modified h-CLAT should be selected to test acid anhydrides and water-insoluble chemicals rather than original the h-CLAT. In the future, we expect that this 5-min exposure in LP medium method will be applied in new in vitro tests for skin sensitization evaluation. Moreover, we believe that these findings may help investigate cytotoxicity mechanisms of chemicals that cannot be evaluated by 
Modified h-CLAT reduces false negatives in skin sensitization tests

conventional, cell-based, in vitro methods.

\section{ACKNOWLEDGMENTS}

This research was partially supported by a Research on Regulatory Science of Pharmaceuticals and Medical Devices grant from the Japan Agency for Medical Research and development (AMED).

Conflict of interest---- The authors declare that there is no conflict of interest.

\section{REFERENCES}

Adler, S., Basketter, D., Creton, S., Pelkonen, O., van Benthem, J., et al. (2011): Alternative (non-animal) methods for cosmetics testing: current status and future prospects-2010. Arch. Toxicol., 85, 367-485.

Aiba, S. (1998): Maturation of dendritic cells induced by cytokines and haptens. Tohoku J. Exp. Med., 184, 159-172.

Aiba, S., Terunuma, A., Manome, H. and Tagami, H. (1997): Dendritic cells differently respond to haptens and irritants by their production of cytokines and expression of co-stimulatory molecules. Eur. J. Immunol., 27, 3031-3038.

Arrighi, J.-F., Rebsamen, M., Rousset, F., Kindler, V. and Hauser, C. (2001): A critical role for p38 mitogen-activated protein kinase in the maturation of human blood-derived dendritic cells induced by lipopolysaccharide, TNF- $\alpha$, and contact sensitizers. J. Immunol., 166, 3837-3845.

Ashikaga, T., Sakaguchi, H., Sono, S., Kosaka, N., Ishikawa, M., Nukada, Y., Miyazawa, M., Ito, Y., Nishiyama, N. and Itagaki, H. (2010): A comparative evaluation of in vitro skin sensitisation tests: the human cell-line activation test (h-CLAT) versus the local lymph node assay (LLNA). Altern. Lab. Anim., 38, 275-284.

Banchereau, J. and Steinman, R.M. (1998): Dendritic cells and the control of immunity. Nature, 392, 245-252.

Basketter, D.A., Alépée, N., Ashikaga, T., Barroso, J., Gilmour, N., Goebel, C., Hibatallah, J., Hoffmann, S., Kern, P., MartinozziTeissier, S., Maxwell, G., Reisinger, K., Sakaguchi, H., Schepky, A., Tailhardat, M. and Templier, M. (2014): Categorization of chemicals according to their relative human skin sensitizing potency. Dermatitis, 25, 11-21.

Basketter, D., White, I.R., McFadden, J.P. and Kimber, I. (2015): Hexyl cinnamal: consideration of skin-sensitizing properties and suitability as a positive control. Cutan. Ocul. Toxicol., 34, 227 231.

Cooper, J.A. 2nd, Saracci, R. and Cole, P. (1979): Describing the validity of carcinogen screening tests. Br. J. Cancer, 39, 87-89.

Cumberbatch, M., Clelland, K., Dearman, R.J. and Kimber, I. (2005): Impact of cutaneous IL-10 on resident epidermal Langerhans' cells and the development of polarized immune responses. J. Immunol., 175, 43-50.

Cumberbatch, M., Dearman, R.J. and Kimber, I. (1997): Langerhans cells require signals from both tumour necrosis factor- $\alpha$ and interleukin-1 $\beta$ for migration. Immunology, 92, 388-395.

De Smedt, A.C., Van Den Heuvel, R.L., Zwi Berneman, N. and Schoeters, G.E. (2001): Modulation of phenotype, cytokine production and stimulatory function of CD34+-derived DC by
$\mathrm{NiCl}(2)$ and SDS. Toxicol. In Vitro, 15, 319-325.

Dearman, R.J., Warbrick, E.V., Humphreys, I.R. and Kimber, I. (2000): Characterization in mice of the immunological properties of five allergenic acid anhydrides. J. Appl. Toxicol., 20, 221230.

Delaine, T., Niklasson, I.B., Emter, R., Luthman, K., Karlberg, A.-T. and Natsch, A. (2011): Structure--activity relationship between the in vivo skin sensitizing potency of analogues of phenyl glycidyl ether and the induction of Nrf2-dependent luciferase activity in the KeratinoSens in vitro assay. Chem. Res. Toxicol., 24, 1312-1318.

Enk, A.H., Angeloni, V.L., Udey, M.C. and Katz, S.I. (1993): An essential role for Langerhans cell-derived IL-1 beta in the initiation of primary immune responses in skin. J. Immunol., 150, 3698-3704.

Gerberick, G.F., Ryan, C.A., Kern, P.S., Schlatter, H., Dearman, R.J., Kimber, I., Patlewicz, G.Y. and Basketter, D.A. (2005): Compilation of historical local lymph node data for evaluation of skin sensitization alternative methods. Dermatitis, 16, 157-202.

Gildea, L.A., Ryan, C.A., Foertsch, L.M., Kennedy, J.M., Dearman, R.J., Kimber, I. and Gerberick, G.F. (2006): Identification of gene expression changes induced by chemical allergens in dendritic cells: opportunities for skin sensitization testing. J. Invest. Dermatol., 126, 1813-1822.

Goodwin, B.F. and Roberts, D.W. (1986): Structure-activity relationships in allergic contact dermatitis. Food Chem. Toxicol., 24, 795-798.

International Agency for Research on Cancer (IARC). (1989): Some glycidyl ethers. IARC Monogr. Eval. Carcinog. Risks Hum., 47, 237-261.

Kanda, Y. (2013): Investigation of the freely available easy-to-use software 'EZR' for medical statistics. Bone Marrow Transplant., 48, 452-458.

Kligman, A.M. (1966): The identification of contact allergens by human assay. 3. The maximization test: a procedure for screening and rating contact sensitizers. J. Invest. Dermatol., 47, 393409

Moffitt, D.L. and Sansom, J.E. (2002): Allergic contact dermatitis from phthalic anhydride/trimellitic anhydride/glycols copolymer in nail varnish. Contact Dermat., 46, 236.

Motolese, A., Truzzi, M., Giannini, A. and Seidenari, S. (1993): Contact dermatitis and contact sensitization among enamellers and decorators in the ceramics industry. Contact Dermat., 28, 59-62.

Narita, K., Vo, P.T., Yamamoto, K., Kojima, H. and Itagaki, H. (2017): Preventing false-negatives in the in vitro skin sensitization testing of acid anhydrides using interleukin- 8 release assays. Toxicol. In Vitro, 42, 69-75.

Natsch, A. and Emter, R. (2008): Skin sensitizers induce antioxidant response element dependent genes: application to the in vitro testing of the sensitization potential of chemicals. Toxicol. Sci., 102, 110-119.

Natsch, A. and Haupt, T. (2013): Utility of rat liver S9 fractions to study skin-sensitizing prohaptens in a modified KeratinoSens assay. Toxicol. Sci., 135, 356-368.

Niklasson, I.B., Broo, K., Jonsson, C., Luthman, K. and Karlberg, A.T. (2009): Reduced sensitizing capacity of epoxy resin systems: a structure-activity relationship study. Chem. Res. Toxicol., 22, 1787-1794.

Nukada, Y., Ashikaga, T., Sakaguchi, H., Sono, S., Mugita, N., Hirota, M., Miyazawa, M., Ito, Y., Sasa, H. and Nishiyama, N. (2011): Predictive performance for human skin sensitiz- 
K. Narita et al.

ing potential of the human cell line activation test (h-CLAT). Contact Dermat., 65, 343-353.

OECD. (2016): OECD guidelines for the testing of chemicals. Test No. 442E: in vitro skin sensitization: human cell line activation test (h-CLAT), adopted July 2016. Paris, France: Organisation for Economic Cooperation and Development.

Opdyke, D.L. (1979): Monographs on fragrance raw materials. Food Cosmet. Toxicol., 17, 259-266.

Patlewicz, G., Dimitrov, S.D., Low, L.K., Kern, P.S., Dimitrova, G.D., Comber, M.I., Aptula, A.O., Phillips, R.D., Niemelä, J., Madsen, C., Wedebye, E.B., Roberts, D.W., Bailey, P.T. and Mekenyan, O.G. (2007): TIMES-SS--a promising tool for the assessment of skin sensitization hazard. A characterization with respect to the OECD validation principles for (Q)SARs and an external evaluation for predictivity. Regul. Toxicol. Pharmacol., 48, 225-239.

Patlewicz, G.Y., Wright, Z.M., Basketter, D.A., Pease, C.K., Lepoittevin, J.P. and Arnau, E.G. (2002): Structure-activity relationships for selected fragrance allergens. Contact Dermat., 47, 219-226.

RIFM. (2007): Data submission to NICEATM. Woodcliff Lake, NJ, USA. RIFM (Research Institute for Fragrance Materials, Inc.)

Rothlein, R., Dustin, M.L., Marlin, S.D. and Springer, T.A. (1986):
A human intercellular adhesion molecule (ICAM-1) distinct from LFA-1. J. Immunol., 137, 1270-1274.

Ryan, C.A., Cruse, L.W., Skinner, R.A., Dearman, R.J., Kimber, I. and Gerberick, G.F. (2002): Examination of a vehicle for use with water soluble materials in the murine local lymph node assay. Food Chem. Toxicol., 40, 1719-1725.

Symington, F.W., Brady, W. and Linsley, P.S. (1993): Expression and function of B7 on human epidermal Langerhans cells. J. Immunol., 150, 1286-1295.

Takenouchi, O., Miyazawa, M., Saito, K., Ashikaga, T. and Sakaguchi, H. (2013): Predictive performance of the human Cell Line Activation Test (h-CLAT) for lipophilic chemicals with high octanol-water partition coefficients. J. Toxicol. Sci., 38, 599-609.

Tsuchiya, S., Yamabe, M., Yamaguchi, Y., Kobayashi, Y., Konno, T. and Tada, K. (1980): Establishment and characterization of a human acute monocytic leukemia cell line (THP-1). Int. J. Cancer, 26, 171-176.

Weltzien, H.U., Moulon, C., Martin, S., Padovan, E., Hartmann, U. and Kohler, J. (1996): T cell immune responses to haptens. Structural models for allergic and autoimmune reactions. Toxicology, 107, 141-151. 